\title{
Application of Plackett Burman and Box Behnken Design for the Optimization of $\beta$-glucosidase Production by Thermophillic Thermomyces dupontii
}

\author{
KINZA NISAR ${ }^{1}$, ROHEENA ABDULLAH ${ }^{1 *}$, AFSHAN KALEEM ${ }^{1}$, MEHWISH IQTEDAR ${ }^{1}$, \\ FAIZA SALEEM ${ }^{1}$, TEHREEMA IFTIKHAR ${ }^{2}$, FARHEEN ASLAM ${ }^{1}$ \\ ${ }^{1}$ Department of Biotechnology Lahore College for Women University, Lahore, Pakistan \\ ${ }^{2}$ Department of Botany Government College University, Lahore, Pakistan
}

\begin{abstract}
A consecutive optimization based on statistical approach was applied for $\beta$-glucosidase production by both wild and mutant T. dupontii. Plackett Burman design (PBD) with two levels was employed in order to screen the significant effect of different nutritional and physical parameters through submerged fermentation. Among all nine variables tested in PBD, incubation time, inoculum size and ammonium sulphate concentration were selected. The Box-Behnken approach was further applied for process optimization. The $\beta$-glucosidase production for both wild and mutant T.dupontii was obtained at $72 \mathrm{~h}$ of incubation, $1.25 \mathrm{~mL}$ inoculum size and $0.25 \%$ ammonium sulphate concentration with relatively $95 \%$ correlation between the experimentally predicted and observed values. The duration of maximum enzyme production in RSM was cost-saving and fast. The quadratic model was in satisfactory adjustment with the experimental data with high $R^{2}$ value which describes $98.90 \%$ of response variability of the model. Moreover, the novel approach of this present work is that, consecutive optimization were applied for maximum $\beta$-glucosidase production using response surface methodology by both wild and mutant thermophillic T. dupontii. Results revealed that thermophillic mutant T. dupontii could be potential candidate for industrial applications.
\end{abstract}

Keywords: thermophillic, quadratic model, submerged fermentation, Response surface methodology, T. dupontii, $\beta$-glucosidase

\section{Introduction}

Cellulases that belongs to hydrolytic group is used for the conversion of lignocellulose into simple sugars. The Cellulases comprises of three major hydrolases including cellobiohydrolase, endoglucanase and $\beta$-glucosidases that act synergistically on cellulose and break into glucose units [1]. Endoglucanase act randomly on the internal glycosidic bonds of amorphous region of cellulose chain resulting into oligosaccharides. Exo $\beta$-glucanase (cellobiohydrolase) hydrolyzes reducing or nonreducing ends of crystalline cellulose into cellobiose whereas $\beta$-glucosidase hydrolyzes alkyl and arylglucoside of cellobiose and cello-dextrin into glucose units. Because of its potential applications, cellulases are becoming more attractive in many industries such as biofuels, pulp and paper, textiles starch and fruit processing [2]. Thermophillic microbes are highly in demand for industrial enzyme production. Fungi are the preferred source for $\beta$-glucosidase production because of their higher enzyme yield [3]. Conventional method optimize one independent factor at a time while keeping the other variables fixed or constant. On the other hand, statistical methods offers many advantages over classical method and considered more reliable and rapid, short lists the significant variables and help to understand the interactions between the variables at different concentrations. Statistical tool such as response surface methodology (RSM) is used for optimization and modeling of numerous variables [4]. Process parameters are optimized in order to get the optimum conditions by interpreting experimental designs with first or second polynomial equations [5]. The aim of present work is to determine the effect of several variables on beta-glucosidase production by both wild and mutant thermophilic T. dupontii using two steps procedure. In the first step Plackett Burman design (PBD) was applied to optimize all

*email: roheena_abdullah@yahoo.com 
environmental and nutritional factors, however in next step Box Behnken-design (BBD) was employed in order to obtain the optimum value of $\beta$-glucosidase production.

\section{Materials and methods}

\section{Microorganism and Inoculum preparation}

In the present study, previously isolated wild Thermomyces dupontii TK-19 and mutant strain Thermomyces dupontii TK-EMS15 were used. About $10 \mathrm{~mL}$ of saline water was added in 3-4 days old culture and conidia were scratched with the help of sterilized inoculating needle in order to break the clumps of conidia. The test tube was shaken vigorously at maximum speed of $800 \mathrm{rpm}$ approximately in order to make a homogeneous suspension.

\section{Shake flask studies}

For submerged fermentation, $25 \mathrm{~mL}$ of sterilized modified medium containing g/L: Yeast extract 10, $\mathrm{MgSO}_{4} 1.7, \mathrm{CaCl}_{2} 0.2, \mathrm{FeCl}_{2} 0.01, \mathrm{KH}_{2} \mathrm{PO}_{4} 2, \mathrm{NH}_{4} \mathrm{Cl}$ 2, $\mathrm{NaCl} 2$, Wheat bran $0.5 \%$ was used with $1 \mathrm{~mL}$ of conidial inoculum [6]. All the flasks were placed in a shaking incubator at $40^{\circ} \mathrm{C}, 120 \mathrm{rpm}$ for $72 \mathrm{~h}$. After fixed fermentation period, fermented broth was centrifuged at $6000 \times \mathrm{g}$ for $20 \mathrm{~min}$. The supernatant obtained after centrifugation were used for enzyme assay. [7]

Assay of $\beta$-glucosidase: $\beta$-glucosidase was determined following the method of Rajoka and Malik.

\section{Experimental designs \\ a.Plackett-Burman Design}

In PBD, screening of nine variables including incubation time, $p \mathrm{H}$, inoculum age and size, volume of medium, lactose, peptone, ammonium sulphate and Tween 80 concentration were set at low and high values which is represented by two levels -1 and +1 , respectively. In PBD interaction between these variables was not considered, therefore, it was used to evaluate and screen the most significant factors that affect the enzyme activity [8]. Design expert version 11 was used to design the experiment. Design expert predicted a set of 12 experiments with possible combinations of nine variables (Table 1).

The PBD is based on the first-order model illustrated in equation (1).

\section{b.Box-Behnken Design}

$$
\mathrm{Y}=\beta 0+\Sigma \beta \mathrm{i} \mathrm{xi}
$$

After getting the results from PBD, the experiment was subjected to BBD. The most significant variables; (X1) Incubation time, (X2) Inoculum size and (X3) Ammonium sulphate concentration were used. These variables were chosen at two coded levels, -1 and +1 for the low and high values, respectively. The Box-Behnken design includes three factors with a set of 15 trials (Table 2). To predict the optimum point in the model, a second order polynomial equation was fitted in order to correlate the relationship between all the selected independent variables and the dependent variable in term of response.

The equation for the three factors was as follows:

$\mathrm{Y}=\beta 0+\beta 1 \mathrm{X} 1+\beta 2 \mathrm{X} 2+\beta 3 \mathrm{X} 3+\beta 12 \mathrm{X} 1 \mathrm{X} 2+\beta 13 \mathrm{X} 1 \mathrm{X} 3+\beta 23 \mathrm{X} 2 \mathrm{X} 3+\beta 11 \mathrm{X} 12+\beta 22 \mathrm{X} 22+\beta 33 \mathrm{X} 2$

where $\mathrm{Y}$ represents the predicted response; $\beta 0$ is the constant of the model; $\mathrm{X} 1, \mathrm{X} 2$ and $\mathrm{X} 3$ denotes the independent variables; $\beta 1, \beta 2$, and $\beta 3$ are the linear coefficients in the model; $\beta 12, \beta 13$, and $\beta 23$ are considered as cross product coefficients; and $\beta 11, \beta 22$, and $\beta 33$ are the quadratic coefficients [9]. 
Table 1. Variables for $\beta$ - glucosidase production using Plackett-Burman Design

\begin{tabular}{|c|c|c|c|c|c|c|c|c|c|c|c|c|c|}
\hline Run & $\mathrm{X} 1$ & $\mathrm{X} 2$ & X3 & $\mathrm{X} 4$ & X5 & X6 & $\mathrm{X} 7$ & X8 & $\mathrm{X} 9$ & \multicolumn{4}{|c|}{$\begin{array}{l}\beta \text { - glucosidase activity }(\mathrm{U} / \mathrm{mL} / \mathrm{min}) \\
\text { Wild }\end{array}$} \\
\hline & hours & & days & $\mathrm{mL}$ & $\mathrm{mL}$ & $\%$ & $\%$ & $\%$ & $\%$ & Actual & Predicted & Actual & Predicted \\
\hline 1 & 72 & 5 & 4 & 1.5 & 25 & 1.5 & 0.3 & 0.3 & 0.5 & 25.00 & 26.17 & 35.00 & 36.17 \\
\hline 2 & 48 & 7 & 4 & 1.5 & 25 & 0.5 & 0.1 & 0.3 & 0.5 & 24.00 & 23.83 & 34.00 & 34.00 \\
\hline 3 & 72 & 7 & 2 & 1.5 & 75 & 1.5 & 0.1 & 0.1 & 0.5 & 24.00 & 23.83 & 34.00 & 34.00 \\
\hline 4 & 72 & 7 & 2 & 0.5 & 25 & 1.5 & 0.1 & 0.3 & 1.5 & 25.00 & 24.17 & 35.00 & 34.00 \\
\hline 5 & 48 & 7 & 2 & 1.5 & 75 & 0.5 & 0.3 & 0.3 & 1.5 & 25.00 & 23.83 & 35.00 & 34.00 \\
\hline 6 & 48 & 5 & 4 & 0.5 & 75 & 1.5 & 0.1 & 0.3 & 1.5 & 21.00 & 21.83 & 31.00 & 31.83 \\
\hline 7 & 72 & 5 & 4 & 1.5 & 75 & 0.5 & 0.1 & 0.1 & 1.5 & 22.00 & 23.83 & 32.00 & 34.00 \\
\hline 8 & 72 & 5 & 2 & 0.5 & 75 & 0.5 & 0.3 & 0.3 & 0.5 & 24.00 & 24.17 & 34.00 & 34.00 \\
\hline 9 & 48 & 5 & 2 & 1.5 & 25 & 1.5 & 0.3 & 0.1 & 1.5 & 23.00 & 21.50 & 34.00 & 31.83 \\
\hline 10 & 48 & 5 & 2 & 0.5 & 25 & 0.5 & 0.1 & 0.1 & 0.5 & 19.00 & 19.50 & 29.00 & 29.67 \\
\hline 11 & 48 & 7 & 4 & 0.5 & 75 & 1.5 & 0.3 & 0.1 & 0.5 & 18.00 & 19.50 & 28.00 & 29.67 \\
\hline 12 & 72 & 7 & 4 & 0.5 & 25 & 0.5 & 0.3 & 0.1 & 1.5 & 24.00 & 21.83 & 34.00 & 31.83 \\
\hline
\end{tabular}

\section{Results and discussions}

\section{Optimization of physical and nutritional parameters by RSM}

In present work PBD was used to screen the factors that significantly affect the $\beta$-glucosidase production by both wild and mutant $T$. dupontii. $\beta$-glucosidase production of nine variables were screened in PBD (Table 1). The optimal $\beta$-glucosidase production was obtained after testing 12 randomized trial runs which was designed by RSM. This enhancement was attained at $p \mathrm{H} \mathrm{5,} \mathrm{Tween} 80$ concentration $0.5 \mathrm{~g} / \mathrm{L}$, volume of medium $25 \mathrm{~mL}$, ammonium sulphate concentration $0.3 \%$, peptone concentration $0.3 \%$, lactose concentration $1.5 \%$, incubation time $72 \mathrm{~h}$, Inoculum age 4 days and inoculum size $1.5 \mathrm{~mL}$. The effect of nine variables on $\beta$-glucosidase production was analyzed on the basis of Pareto chart (Figure 1). Pareto chart creates a reference line (t-value limit) that helps to estimate the rank of each factor in a descending order. Any factor which extends or passes the reference line is theoretically significant. The data from Pareto chart revealed that out of all nine factors, three variables such as (X1) incubation time, (X4) inoculum size and (X8) ammonium sulphate concentration had a positive effect on $\beta$-glucosidase production, while the remaining factors did not show any significant effect on $\beta$-glucosidase production. Significant increase in $\beta$-glucosidase production was obtained at $72 \mathrm{~h}$ of incubation time, $1.25 \mathrm{~mL}$ inoculum size and $0.25 \%$ ammonium sulphate concentration. The polynomial model which predicts the $\beta$-glucosidase production obtained from (PB) predicted regression analysis expressed in terms of coded factors in equation 3 and 4.

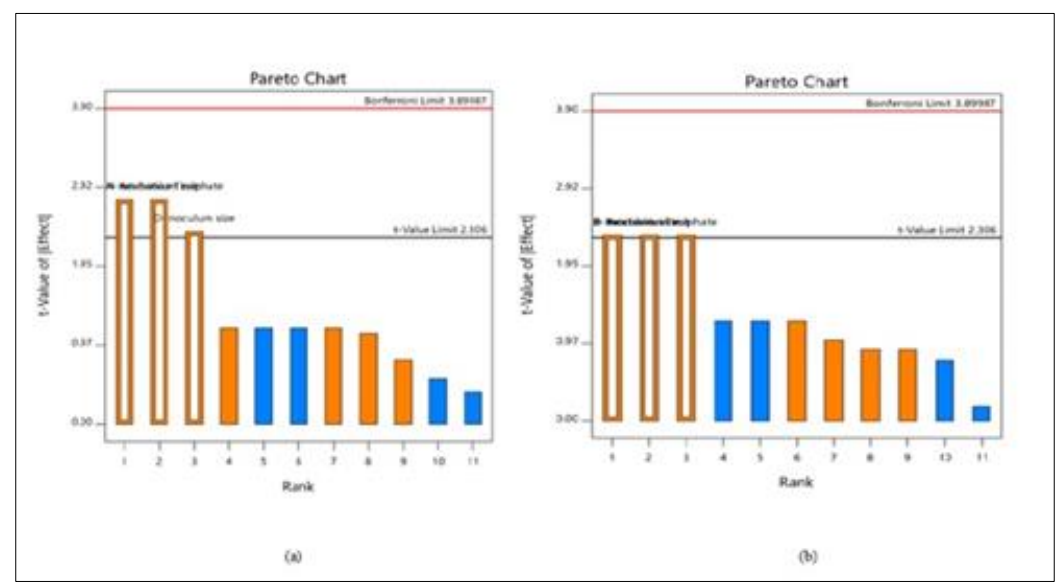

Figure 1. Effects of Pareto plots on $\beta$ - glucosidase production (a) Wild $T$. dupontii (b) Mutant $T$. dupontii 
$\beta$-glucosidase production of Wild strain $(\mathrm{Y})=+10.83333+0.097222 \mathrm{X} 1+0.500000 \mathrm{X} 2-0.500000 \mathrm{X} 3$ $+2.00000 \mathrm{X} 4-0.020000 \mathrm{X} 5-0.333333 \mathrm{X} 6+3.33333 \mathrm{X} 7+11.66667 \mathrm{X} 8+1.000000 \mathrm{X} 9$

$$
\begin{aligned}
& \beta \text {-glucosidase production of Mutant strain }(\mathrm{Y})=+21.75000+0.090278 \text { X1+0.416667 X2-0.583333 } \\
& \text { X3+2.16667 X4-0.023333 X5 0.166667 X6+4.16667 X7+10.83333 X8+1.16667 X9 }
\end{aligned}
$$

\section{Model Fitting by Response Surface Method (RSM)}

The optimization of most significant variables affecting the $\beta$-glucosidase production were further tested in BBD and regression equation was developed, relating to the response variable $Y$ to coded levels of the independent variables. The levels for the significant variables, namely incubation time, inoculum size and ammonium sulphate concentration were varied, however the non-significant factors with negative values stabilized at lower $(-1)$ levels whereas positive values stabilized at high levels $(+1)$. To find the optimum value of $\beta$-glucosidase production, the important independent variables Incubation time, X1; inoculum size, X4 and ammonium sulphate concentration, X8 were further investigated at two levels. Table 2 represents the design matrix for the variables, given in both coded and actual units. The results from the experimental design indicate that, incubation time, inoculum size and ammonium sulphate, significantly increases $\beta$-glucosidase production by both wild and mutant strain of $T$. dupontii. F-value greater than $\mathrm{P}$ value indicate that the model was significant with $95 \%$ confidence level. Lower P-value (probability < 0.0001) indicates the significance of the model. $\mathrm{R}$ value in the model indicates the degree of precision. High correlation $\mathrm{R}^{2}=0.9$ was observed between actual and experimentally predicted values (Table 3 ). $\mathrm{R}^{2}$ which represent the coefficient of determination has a value of 0.9890 , which describes $98.90 \%$ of response variability in the model [10].The adjusted $R^{2}$ coefficient $(0.9)$ was also high enough to confirm the significance of the model which was confirmed in scatter plot. In the evaluation of experiments, the reliability of the model depends upon the certain assumptions, including residuals should have normal distribution with zero mean and constant variance $\left(\partial^{2}\right)$. Figure 2 a shows that most of the points were on the diagonal line which is due to the high $\mathrm{R}^{2}$ value. It also shows that analysis of residuals were normal and no deviation was found in the normality of the residuals. However, the assumption for the normality of the experiment was confirmed. Figure $2 \mathrm{~b}$ shows the constancy of the variances of the residuals. The assumption when there is no particular trend in the given graph, then variance is constant and it is accepted. So the given diagram had no particular trend indicating that presumption of constant variance is confirmed. Figure $2 \mathrm{c}$ shows that model graph for beta-glucosidase is well suited to the experimental data.

To predict the optimal point, within the experimental data; a second-order polynomial model was fitted to the experimental $\beta$-glucosidase production and equation was generated $(5,6)$.
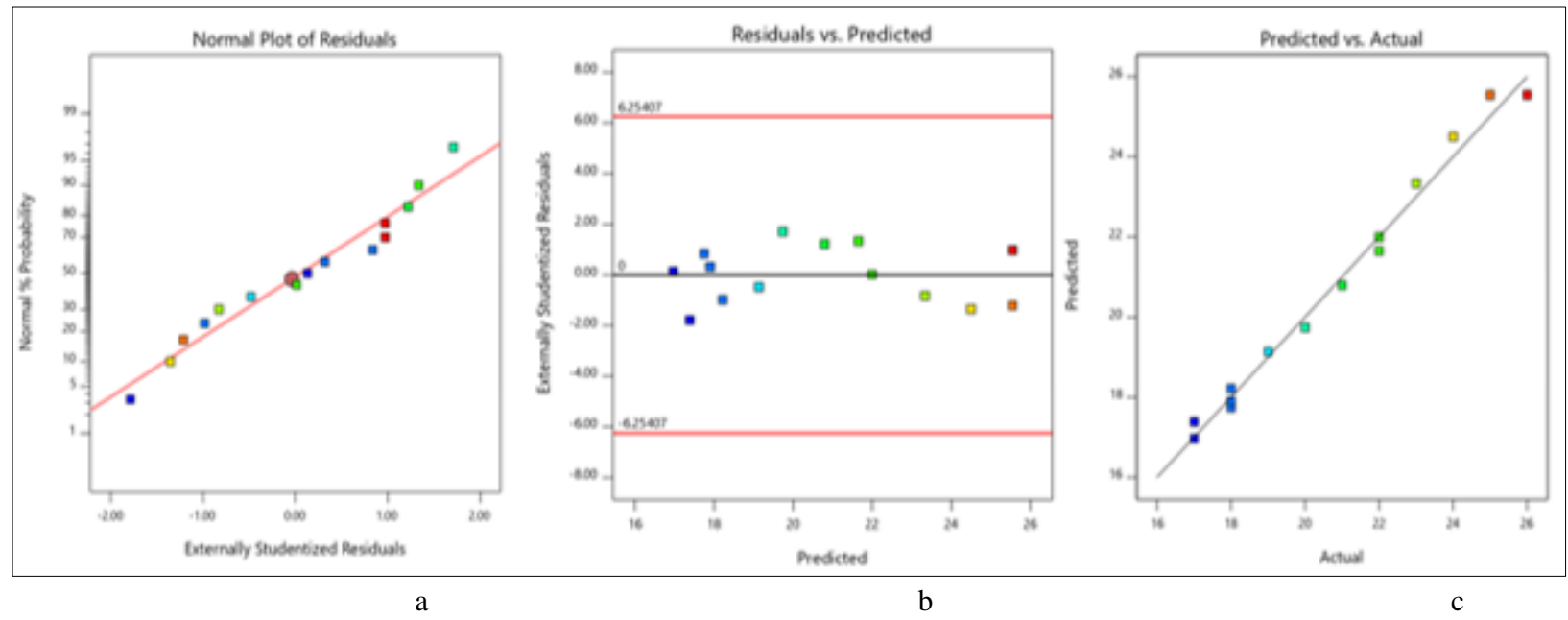

Figure 2. Distributive plotting of experimental data versus predicted values for $\beta$-glucosidase production 


\section{Revista de Chimie}

$\beta$-glucosidase of wild $T$. dupontii $(\mathrm{Y})=+25.54+1.37 \mathrm{X} 1+1.14 \mathrm{X} 4-0.7582 \mathrm{X} 8+0.7500 \mathrm{X} 1 \mathrm{X} 4-0.5000$

$\beta$-glucosidase of mutant $T$. dupontii $(\mathrm{Y})=+36.54+1.37 \mathrm{X} 1+1.14 \mathrm{X} 4-0.7582 \mathrm{X} 8+0.7500 \mathrm{X} 1 \mathrm{X} 4$ $0.5000 \mathrm{X} 1 \mathrm{X} 8-0.6113 \mathrm{X} 4 \mathrm{X} 8-4.41 \mathrm{X} 1^{2}-2.40 \mathrm{X} 4^{2}-2.12 \mathrm{X}^{2}$

Table 2. Variables for $\beta$ - glucosidase production using BBD

\begin{tabular}{|c|c|c|c|c|c|c|c|}
\hline \multirow[t]{3}{*}{ Run } & \multirow[t]{2}{*}{$\mathrm{X} 1$} & \multirow{2}{*}{\multicolumn{2}{|c|}{$\mathrm{X} 4$}} & \multicolumn{3}{|c|}{$\beta$ - glucosidase activity $(\mathrm{U} / \mathrm{mL} / \mathrm{min})$} & \multirow[b]{3}{*}{ Predicted } \\
\hline & & & & \multirow{2}{*}{$\frac{\text { Wild }}{\text { Actual }}$} & & Mutant & \\
\hline & Days & $\mathrm{mL}$ & $\%$ & & Predicted & Actual & \\
\hline 1 & 3 & 0.5 & 0.4 & 20.00 & 19.74 & 31.00 & 30.74 \\
\hline 2 & 3 & 2 & 0.2 & 24.00 & 24.50 & 35.00 & 35.50 \\
\hline 3 & 1 & 2 & 0.25 & 18.00 & 17.75 & 29.00 & 28.75 \\
\hline 4 & 5 & 1.25 & 0.4 & 19.00 & 19.14 & 30.00 & 30.14 \\
\hline 5 & 3 & 1.25 & 0.25 & 26.00 & 25.54 & 37.00 & 36.54 \\
\hline 6 & 3 & 1.25 & 0.25 & 26.00 & 25.54 & 37.00 & 36.54 \\
\hline 7 & 5 & 0.5 & 0.25 & 18.00 & 18.22 & 29.00 & 29.22 \\
\hline 8 & 3 & 1 & 0.1 & 23.00 & 23.34 & 34.00 & 34.34 \\
\hline 9 & 1 & 1.25 & 0.4 & 17.00 & 17.39 & 28.00 & 28.39 \\
\hline 10 & 3 & 2 & 0.4 & 21.00 & 20.80 & 32.00 & 31.80 \\
\hline 11 & 1 & 0.5 & 0.25 & 17.00 & 16.97 & 28.00 & 27.97 \\
\hline 12 & 5 & 1.25 & 0.1 & 22.00 & 21.65 & 33.00 & 32.65 \\
\hline 13 & 5 & 2 & 0.25 & 22.00 & 22.00 & 33.00 & 33.00 \\
\hline 14 & 3 & 1.25 & 0.25 & 25.00 & 25.54 & 36.00 & 36.54 \\
\hline 15 & 1 & 1.25 & 0.1 & 18.00 & 17.90 & 29.00 & 28.90 \\
\hline
\end{tabular}

Table 3. Summary of the ANOVA for $\beta$-glucosidase production by T.dupontii

\begin{tabular}{|c|c|c|c|c|c|c|}
\hline Source & $\begin{array}{c}\text { Sum of } \\
\text { Squares }\end{array}$ & df & Mean Square & F-value & p-value & \\
\hline Model & 143.34 & 9 & 15.93 & 49.86 & 0.0002 & significant \\
\hline A-Incubation Time & 15.12 & 1 & 15.12 & 47.35 & 0.0010 & \\
\hline B-Inoculum size & 7.37 & 1 & 7.37 & 23.07 & 0.0049 & \\
\hline $\begin{array}{l}\text { C-Ammonium } \\
\text { sulphate }\end{array}$ & 3.59 & 1 & 3.59 & 11.24 & 0.0203 & \\
\hline $\mathrm{AB}$ & 2.25 & 1 & 2.25 & 7.04 & 0.0452 & \\
\hline $\mathrm{AC}$ & 1.0000 & 1 & 1.0000 & 3.13 & 0.1371 & \\
\hline $\mathrm{BC}$ & 0.6717 & 1 & 0.6717 & 2.10 & 0.2067 & \\
\hline $\mathrm{A}^{2}$ & 70.65 & 1 & 70.65 & 221.17 & $<0.0001$ & \\
\hline $\mathrm{B}^{2}$ & 16.58 & 1 & 16.58 & 51.92 & 0.0008 & \\
\hline $\mathrm{C}^{2}$ & 13.57 & 1 & 13.57 & 42.47 & 0.0013 & \\
\hline Residual & 1.60 & 5 & 0.3194 & & & \\
\hline Lack of Fit & 0.9305 & 3 & 0.3102 & 0.9305 & 0.5553 & not significant \\
\hline Pure Error & 0.6667 & 2 & 0.3333 & & & \\
\hline Cor Total & 144.93 & 14 & & & & \\
\hline
\end{tabular}

where $\mathrm{Y}$ is the $\beta$-glucosidase production, while $\mathrm{X} 1, \mathrm{X} 4$, and $\mathrm{X} 8$ are incubation time, inoculum size and ammonium sulphate concentration respectively. Predicted $\beta$-glucosidase production $(25.54 ; 36.54 \mathrm{U} / \mathrm{mL}$ $/ \mathrm{min}$ ) of wild and mutant $T$. dupontii respectively was obtained at $72 \mathrm{~h}$ of incubation time, 
$1.25 \mathrm{~mL}$ inoculum size and $0.25 \%$ ammonium sulphate concentration, compared to actual value of (26; $37 \mathrm{U} / \mathrm{mL} / \mathrm{min})$.

3D surface response and contour plots were generated by considering all possible combinations of independent variables such as incubation time, inoculum size and ammonium sulphate concentration. Figure 3 clearly shows the variables with their optimal setting. Figure $3 a$ denotes the interaction between incubation time and inoculum size for both wild and mutant $T$. dupontii. The maximum $\beta$-glucosidase production was noticed at $1.25 \mathrm{~mL}$ inoculum size and $72 \mathrm{~h}$ of incubation time. There was gradual decline of $\beta$-glucosidase production in contour graphs with increased in inoculum size and incubation time. The decrease in $\beta$-glucosidase production after $72 \mathrm{~h}$ might be due to denaturation of the enzyme or may be due to cumulative effect of cellobiose, a dimer of glucose which is known to inhibit both endoglucanase and $\beta$-glucosidase [11]. Our findings are in accordance with Mahapatra [1]; who observed maximum $\beta$-glucosidase production at $72 \mathrm{~h}$ of incubation. Whereas enhanced production at $1.25 \mathrm{~mL}$ inoculum size might be due to the production of sufficient amount of conidia, which help to synthesize ideal enzyme productivity. A decline in enzyme activity was noticed above or below the optimal concentration. Lower $\beta$-glucosidase production was recorded below the $1.25 \mathrm{~mL}$ inoculum size which was probably due to the presence of less conidial cells and become deficient to use the fermentation medium; however, the less productivity at higher inoculum size was possibly due to the nutritional imbalance and overgrowth that reduces the enzyme production [12].

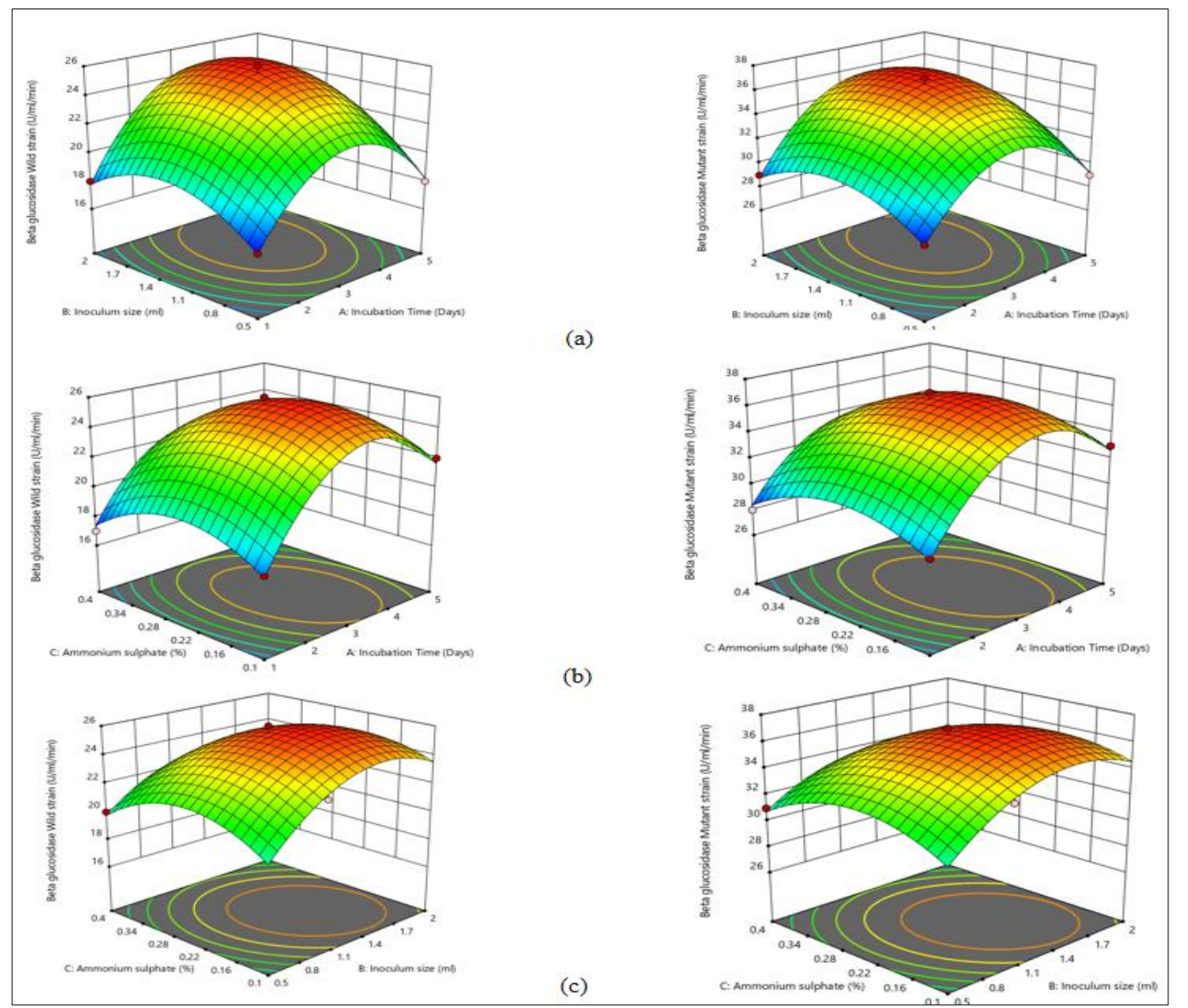

Figure 3. Response surface and Contour plots on $\beta$-glucosidase production by wild and mutant T.dupontii. (a) Incubation time and inoculum size (b) Ammonium sulphate concentration and incubation time (c) Ammonium sulphate concentration and inoculum size

Figure $3 \mathrm{~b}$ depicts the relationship between incubation time and ammonium sulphate concentration for both wild and mutant $T$. dupontii. Optimal $\beta$-glucosidase production was noticed in contour plots at 
$72 \mathrm{~h}$ of incubation and $0.25 \%$ of ammonium sulphate concentration. Less $\beta$-glucosidase production was found above or below the maximal level. Enhancement of $\beta$-glucosidase production with $0.25 \%$ addition of ammonium sulphate might be due to the fact that ammonium sulphate provides both the ammonium $\left(\mathrm{NH}_{4}+\right)$ and sulfate ions $\left(\mathrm{SO}_{4}{ }^{2}\right)$ for conidial growth [13]. Ammonium sulphate was reported as best nitrogen source for $\beta$-glucosidase production [14]. On the other hand time course profile had significant effect on enzyme production, less production above $72 \mathrm{~h}$ may be due to insufficient growth time, depletion of nutrients or accumulation of some byproducts such as proteases in the fermentation medium that causes the autolysis of cells [15].

Figure $3 \mathrm{c}$ represents the correlation between inoculum size and ammonium sulphate concentration. Higher level of $\beta$-glucosidase production was noticed at $0.25 \%$ of ammonium sulphate concentration and $1.25 \mathrm{~mL}$ of inoculum size. Any change in the optimum level decreases the $\beta$-glucosidase productivity. Low inoculum size shortened the microbial lag phase, whereas inoculum size beyond the optimal value lower the level of enzyme formation due to the overcrowding or excess numbers of fungal spores [16].

\section{Conclusions}

Process optimization of $\beta$-glucosidase production was carried by applying RSM. Plackett-Burman Design and Box-Behnken Design were chosen for this purpose. The enhanced production of $\beta$ glucosidase was recorded after execution of whole process of optimization. The significance of application of this model was that it reduces the time of accomplishment of the whole process by reducing the number of trials. The present findings also suggest that thermophillic mutant Thermomyces dupontii EMS15 may have significant commercial values for industrial applications.

\section{References}

1. MAHAPATRA, S., VICKRAM, A., SRIDHARAN, T., PARAMESWARI, R., PATHY, M. R., 3 Biotech., 6, no. 2, 2016, p. 213

2. AHMED, A., NASIM, F., BATOOL, K., BIBI, A., J. Appl. Environ. Microbiol., 5, 2017, p. 46

3.SULMAN, S., REHMAN, A., Pak. J. Zool., 45, 2013, p. 816

4. BEHERA, S. K., MEENA, H., CHAKRABORTY, S., MEIKAP, B., Int. J. Min Sci. Technol., 28 , no. 4, 2018, p. 629

5. VAITHANOMSAT, P., SONGPIM, M., MALAPANT, T., KOSUGI, A., THANAPASE, W., MORI, Y., Int. J. Microbiol., 2011, p. 9

6. PRASANNA, H., RAMANJANEYULU, G., REDDY, B.R., 3 Biotech., 6, no. 2, 2016, p.162

7. RAJOKA, M.I., MALIK, K.A., Bioresour. Technol., 59, no. 1,1997, p. 27

8. JOB, J., SUKUMARAN, R. K., JAYACHANDRAN, K., World J. Microbiol. Biotechnol., 26, no. 8, 2010, p. 1391

9. EL-NAGGAR, N. E. A., HAROUN, S., OWIS, E., SHERIEF, A. Prep. Biochem. Biotech., 45, no. 6, 2015, p. 587

10. GUNNY, A. A. N., ARBAIN, D., JAMAL, P., GUMBA, R. E., Saudi J. Biol. Sci., 22, no. 4, 2015, p. 483

11. AZZAZ, H. H., MURAD, H. A., KHOLIF, A. M., HANFY, M. A., GAWAD, M. A., RES. $J$. Microbiol., 7, no. 1, 2012, p. 31.

12. DINARVAND, M., REZAEE, M., FOROUGHI, M., BRAZ. J. Microbiol., 48, no. 3, 2017, p. 441

13. MALIK, S.K., MUKHTAR, H., FAROOQI, A. A., HAQ, I., Pak. J. Bot., 42, no. 6, 2010, p. 4251

14. YADAV, P., SHRUTHI, K., PRASAD, B., CHANDRA, M., Int. J. Curr. Microbiol. App. Sci., 5, no. 12,2016, p. 564

15. AKINYELE, J. B., OLANIYI, O. O., Innov. Rom. Food Biotechnol., 13, 2013, p. 79

16. AFZAL, A., KAMRAN, M., MEHMOOD, S., Adv. Biosci. Biotechnol., 5, no. 5, 2014, p. 433

Manuscript received: 30.11 .2019 